\title{
Age-Related Depletion of the Cell Population in the Human Trabecular Meshwork
}

\author{
IAN GRIERSON and ROBIN C. HOWES \\ London
}

\begin{abstract}
Summary
The number of cells in the human trabecular meshwork was assessed for counting meshwork cell nuclei in semithin Araldite sections cut in the meridonal plane. The counts of nuclei decreased with increasing age and the decrease was associated with all regions of the meshwork. The appropriate regression equation and a mean length for meshwork nuclei was used to estimate cell numbers. At 20 years of age the estimated cell number for the whole meshwork was 763,000 which decreased to 403,000 cells by 80 years with a loss rate of 6,000 cells per year.
\end{abstract}

Ageing changes in the outflow system of the human eye include trabecular thickening, trabecular fusions, accumulation of wide spacing collagen, hyperpigmentation of meshwork cells, alteration to the extracellular matrix of the endothelial meshwork and loss of giant vacuoles from the endothelium of Schlemm's canal. ${ }^{1-6}$ These changes, for the most part, are likely to result in an increase in resistance to aqueous outflow as we age $^{7}$ but as intraocular pressure remains more or less constant throughout life, decrease in aqueous production is sufficient to compensate for this. ${ }^{7}$

It is important carefully to document and quantify age related alterations in the outflow system because the pathological changes associated with primary open angle glaucoma and possibly also some forms of secondary glaucoma may be an exacerbation of the normal ageing process. ${ }^{8}$ Of particular interest is the finding of Alvarado et al, ${ }^{9,10}$ that the cellularity of the trabecular meshwork decreases as we age. Indeed progressive depression of the cell population may be the key event triggering off many of the other connective tissue changes we describe. Clearly, careful documentation of the altera- tions in the meshwork cell population is essential both for our understanding of ageing and as a baseline to evaluate excessive cell loss in glaucoma. ${ }^{4,9,10} \mathrm{We}$ have reported alterations in the cell population of the human meshwork in a preliminary study of 19 eyes. ${ }^{4}$ In the present report we have extended the investigation to 44 eyes.

\section{Materials and Methods}

A series of 44 eyes aged between five months post natal and 92 years provided the material for investigation. Segments of angular tissue were fixed in buffered glutaraldehyde, postfixed in buffered osmium tetroxide, dehydrated and embedded in Araldite. Further details of these eyes are provided in another publication. ${ }^{5}$

Sections (approximately $1 \mu \mathrm{m}$ thick) were cut in the meridional plane from 5 randomly chosen tissue blocks per eye and stained with toluidine blue. One section from each block was taken for counting meshwork cell nuclei. All counts were conducted under the $\times 100$ oil immersion lens of a light microscope and nuclei were counted from the total meshwork, the anterior portion of the meshwork, the central meshwork, the posterior portion of the meshwork and the endothelial meshwork. We considered the total meshwork to extend from Sch- 


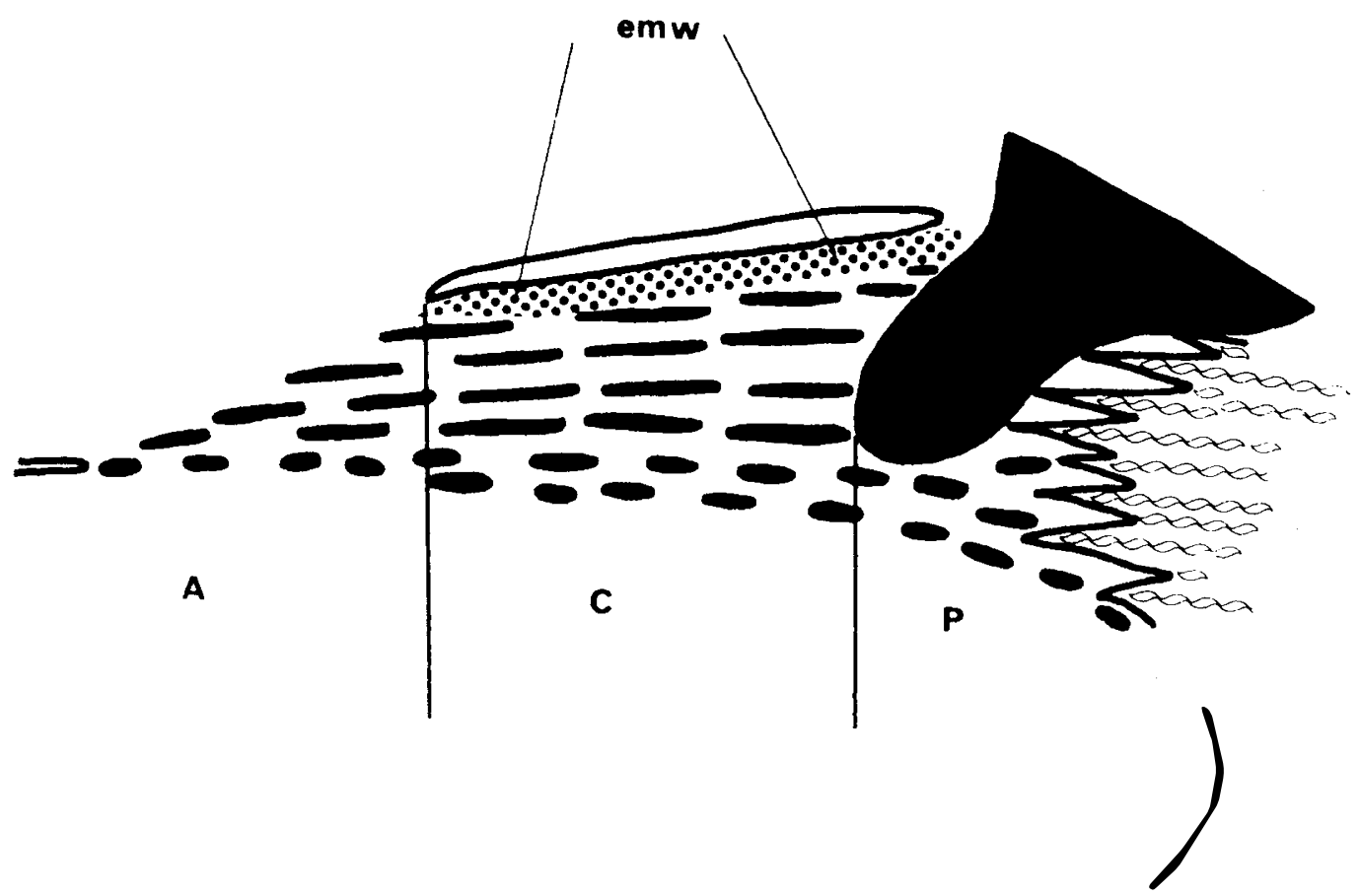

Fig. 1. Diagram of the regions counted. a anterior meshwork, c central meshwork, p posterior meshwork and emw endothelial meshwork.

walbe's line to the anterior limit of the scleral spur and to include a posterior portion beneath the spur limited by the spur, chamber angle and the meshwork insertion of the ciliary muscle. The anterior portion of the meshwork extended from Schwalbe's line to the anterior limit of Schlemm's canal. The endothelial meshwork was a non-trabecular zone 3-5 cells thick immediately below the endothelial monolayer lining the inner aspect of Schlemm's canal. If the anterior, posterior and endothelial meshwork count was subtracted from the total count, a value for the central meshwork region was obtained (Fig. 1). Distinction was made between nuclei belonging to meshwork cells and nuclei of non-native (inflammatory) cells. Intraobserver errors for each nuclear count were in the order of 10 per cent and interobserver errors did not exceed 15 per cent.

An attempt was made to establish a baseline for nuclear length in the plane of section and to determine whether this length altered with ageing. From our series, a group of 5 eyes from different decades were taken adopting the same approach as outlined in a previous study of nuclei in the endothelium of Schlemm's canal. ${ }^{5}$ From one tissue block from each eye, 25 serial $1 \mu \mathrm{m}$ sections were cut, stained (Toluidine blue) and photographed under the $\times 40$ objective lens of a light microscope. From the photographic enlargements, meshwork cell nuclei were followed into and then out of section by two independent observers so that values for the length of a sample population of meshwork cell nuclei could be determined.

\section{Results}

The trabecular meshwork in the first decade is distinguished by delicate trabeculae lined by abundant cells. By 30 years or so the trabeculae are still delicate, cells remain numerous but occasional fusions are seen between adjacent trabeculae (Fig. 2A). In later years cell loss, as noted by the absence of nuclei, becomes progressively more obvious. By 70 years there is focal trabecular thickening, cells are elongated and thin and fusions between trabeculae are plentiful (Figs. 2B and C).

The relationship between numbers of nuclei in the total meshwork area and age is shown in Figure 3. This relationship is satisfied by a regression equation with a negative slope and is significantly different from the horizontal (Table I). Within the total meshwork area, all four regions demonstrated decreases in nuclear count with increasing age 

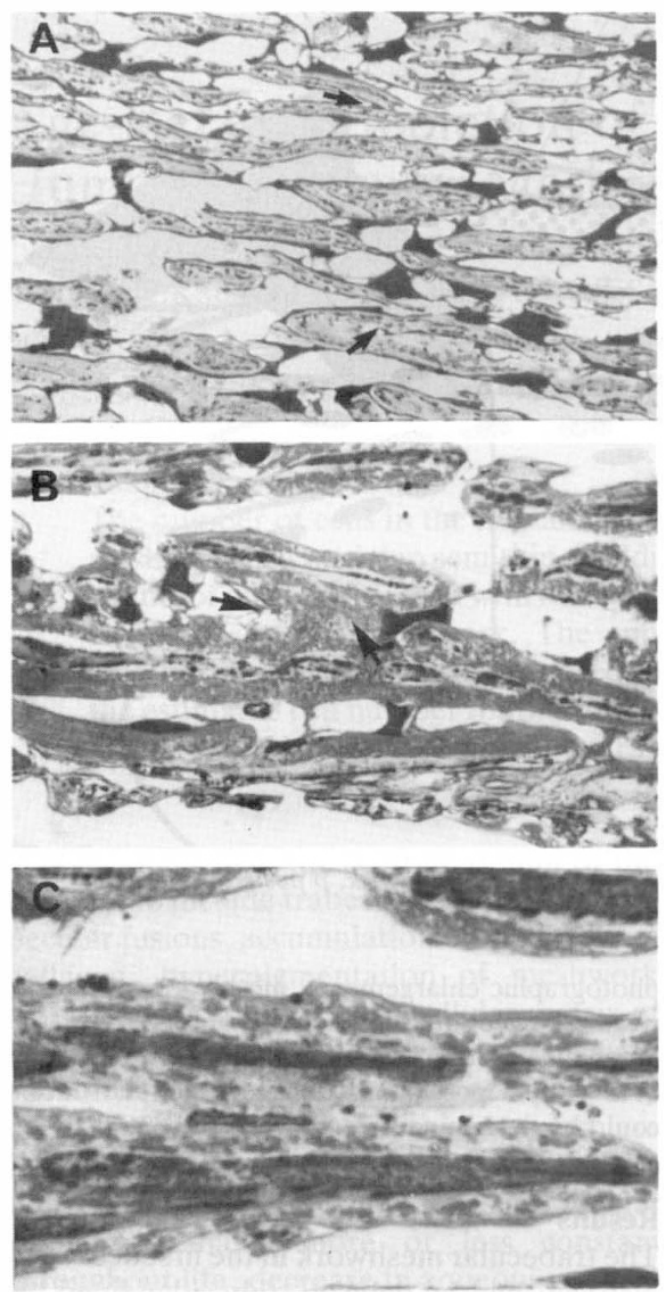

Fig. 2. Light micrographs of the meshwork cut in the meridional plane. (a) The trabeculae from a 31 year old are delicate and there are many covering cells. Some fusions between adjacent trabeculae can be identified (arrows). (b) In a 76 year old there are fewer cells and extensive areas off usion are evident (arrows). (c) At 76 years focal areas of trabecular thickening are prominent (Toluidine blue stained $1 \mu \mathrm{m}$ sections $a \times 600 ; b \times$ $1,000 ; c \times 1,500)$.

(Fig. 4). As is evident in Table I, the negative relationship in each case is significant. A correlation matrix shows a close relationship between regional decrease in nuclear incidence for all regions (Table II). The rate of nuclear loss is least in the endothelial meshwork and greatest in the central region. Comparing slopes to determine differences in the rate of nuclear decrease shows no significant difference between the slopes for the endothelial, anterior and posterior meshworks but the slope for the central meshwork was significantly steeper than for the other three regions $(\mathrm{P}<0.001)$ in all cases. Although there is some variation in the length of the nuclei reconstructed from serial sections there is no clear cut age relationship (Table III). If we assume one nucleus per cell and the meshwork is 36 $\mathrm{mm}$ round the 360 degree circumference at the limbus, then using the appropriate regression equation, an average nuclear length of $9.1 \mu \mathrm{m}$ (from Table III), and using the Abercrombie correction to account for section thickness $^{11}$ we calculate that there are approximately 760,000 cells in the meshwork at 20 years of age but only 400,000 at 80 years with a loss of 6,000 cells per year (Table IV).

\section{Discussion}

Alvarado and co-workers showed that the cellularity of the human meshwork decreased with age.$^{9,10}$ Our own preliminary findings in a pilot study ${ }^{4}$ were extended in this investigation from 19 to 44 subjects and confirmed Alvarado's recent research. The decrease in cell nuclei is evident in all regions of the meshwork including the endothelial meshwork. McMenamin and Lee ${ }^{12}$ found no substantial decrease in the area occupied by cells in an electron microscopic quantitative study of the endothelial meshwork. Although the findings

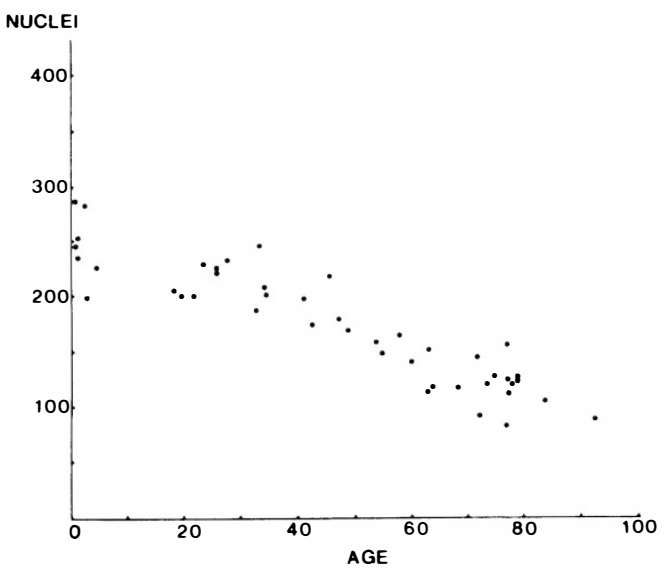

Fig. 3 Scatter diagram showing the relationship between the total counts of nuclei in a meridional section of the meshwork and age. 
Table I. The regression equations from the scatter diagrams shown in Figures 3 and 4. In each case the slope of the regression line is significantly different from the horizontal

Total meshwork:

counts of nuclei $=-1.68 \times$ age +247.63

$\mathrm{r}=0.8436$

$\mathrm{R}^{2}=0.7117 \quad \mathrm{P}<0.0001$

Endothelial meshwork:

counts of nuclei $=-0.19 \times$ age +32.11

$\mathrm{r}=0.7206$

$\mathrm{R}^{2}=0.5193 \quad \mathrm{P}<0.0001$

Anterior meshwork:

counts of nuclei $=-0.41 \times$ age +62.89

$\mathrm{r}=0.7828$

$\mathrm{R}^{2}=0.6128 \quad \mathrm{P}<0.0001$

Posterior meshwork:

counts of nuclei $=-0.25 \times$ age +38.31

$\mathrm{r}=0.8436$

$\mathrm{R}^{2}=0.7117 \quad \mathrm{P}<0.0001$

Central meshwork:

counts of nuclei $=-0.83 \times$ age +114.27

$\mathrm{r}=0.8428$

$\mathrm{R}^{2}=0.7103 \quad \mathrm{P}<0.0001$

of McMenamin and Lee ${ }^{12}$ may be partly explained by reduced numbers of cells becoming enlarged, essentially our own findings and those of Alvarado ${ }^{9.10}$ disagree with McMenamin and Lee. Limited studies of the injured rabbit outflow system (our own unpublished results) and the rabbit and cat outflow system induced to phagocytose ${ }^{16}$ indicate that there is limited incorporation of ${ }^{3} \mathrm{H}$-thymidine by meshwork cells. Whether the incorporation represents cell nuclei entering S-phase or DNA repair within nuclei remains to be established. However, it would seem likely that the normal meshwork has such a limited capacity to replace cellular loss that we could consider that the population of cells we are born with is, for all intents and purposes, all the cells we ever have.

If a linear regression equation is applied to our data it would seem that the meshwork population is halved over a life time, decreasing from over 750,000 at 20 years to approximately 400,000 by 80 years of age. It may well be that the relationship between cell numbers (as reflected in a count of nuclei) and age is not linear throughout life. Indeed, it has been shown that when foetal tissue is also taken into consideration the relationship is decidedly non-linear with particularly high counts in the foetal and immediate post-natal periods. ${ }^{9}$ However, in early life corrections are required to account for the increasing size of the meshwork as the eye enlarges. For the purposes of the present study, an arbitrary size of $36 \mathrm{~mm}$ is used as a constant for our calculations and is clearly inappropriate in the first decade. Whether or not there is a true cell loss in the first decade or merely a 'spreading out' of a static cell population is beyond the scope of our limited data.

It would seem to be a reasonable working hypothesis that most ageing changes in the outflow system relate either directly to the progressive cell loss or result from aberrant reparative fibrotic activity by the surviving meshwork cells. Thus trabecular fusion ${ }^{4}$ an age related event, can be explained by depletion in the cell population resulting in an incomplete cover on the trabeculae. Without a continuous cell cover, adhesions (synaeceae) between denuded portions of adjacent trabeculae can develop. It is known that meshwork cells can become 'activated' when the meshwork is insulted ${ }^{14}$ and 'activation' is associated with an increase in cytoplasmic rough endoplasmic reticulum, Golgi vesicles

Table II. A correlation matrix of nuclear relationships in the various regions of the meshwork. The coefficients are significant at the $P<0.01$ level or better

\begin{tabular}{lccccc}
\hline & $\begin{array}{c}\text { Total } \\
\text { meshwork }\end{array}$ & $\begin{array}{c}\text { Endothelial } \\
\text { meshwork }\end{array}$ & $\begin{array}{c}\text { Anterior } \\
\text { meshwork }\end{array}$ & $\begin{array}{c}\text { Posterior } \\
\text { meshwork }\end{array}$ & \\
meshwork
\end{tabular}



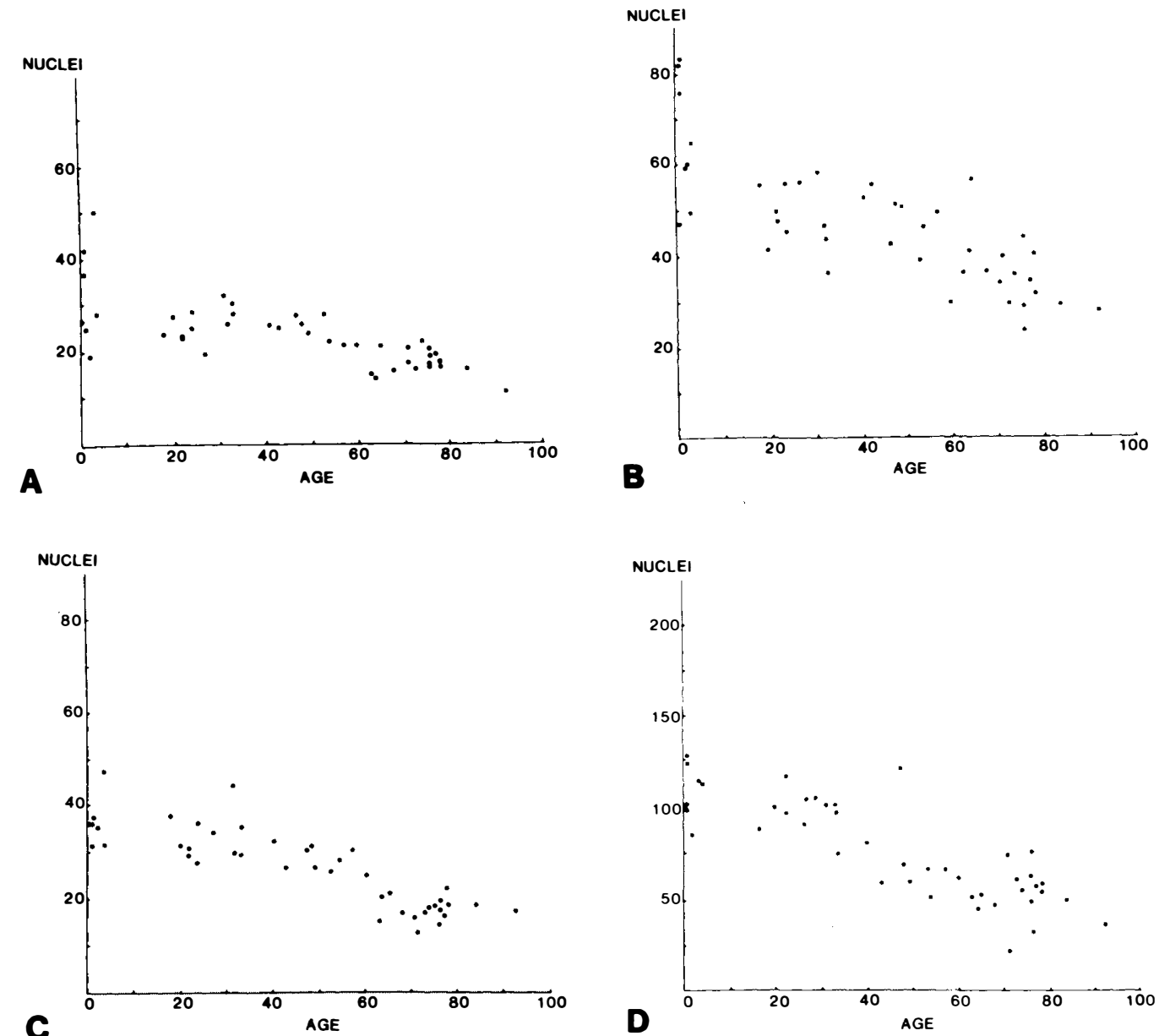

Fig. 4. Scatter diagrams showing the relationship between counts of nuclei in the various regions of the meshwork and age. (a) endothelial meshwork, (b) anterior meshwork, (c) posterior meshwork and (d) central meshwork.

Table III. Mean length of nuclei from 25 sequential $1 \mu \mathrm{m}$ sections from one tissue block for each of the 5 eyes in the series

\begin{tabular}{ccc}
\hline $\begin{array}{c}\text { Age } \\
\text { (years) }\end{array}$ & $\begin{array}{c}\text { Number of } \\
\text { nuclei }\end{array}$ & $\begin{array}{c}\text { Mean length in } \\
\text { sections } \pm S D\end{array}$ \\
\hline 2 & 23 & $8.3 \pm 2.3$ \\
22 & 18 & $10.9 \pm 2.6$ \\
53 & 21 & $9.6 \pm 2.7$ \\
76 & 16 & $7.9 \pm 2.2$ \\
92 & 21 & $8.5 \pm 2.2$ \\
\hline & 99 & $9.1 \pm 2.4$ \\
\hline
\end{tabular}

and other organelles which indicate increased synthesis. Indeed meshwork cells in culture with the morphological characteristics of 'activated' cells incorporate several fold greater quantities of ${ }^{3} \mathrm{H}$-proline and ${ }^{3} \mathrm{H}$-glucosamine than cultures with morphological features closer to normal meshwork. ${ }^{15}$ It may be that a process somewhat akin to 'activation' is induced in a proportion of the 'surviving' cells which accounts for the localised trabecular thickening ${ }^{2,3,12}$ and accumulation of various extracellular materials in the endothelial meshwork $^{3,6,12}$ which are characteristics of the elderly meshwork tissue.

The question arises as to the reasons for the 
Table IV. Using the appropriate regression equations (Table II) and the overall mean length of nuclei (Table III) the number of meshwork cells at different ages were estimated

\begin{tabular}{|c|c|c|c|}
\hline Area & $\begin{array}{l}\text { Estimated } \\
\text { no. of } \\
\text { meshwork } \\
\text { cells at } \\
20 \text { years }\end{array}$ & $\begin{array}{c}\text { Estimated } \\
\text { no. of } \\
\text { meshwork } \\
\text { cells at } \\
80 \text { years }\end{array}$ & $\begin{array}{c}\text { Loss } \\
\text { rate } \\
\text { per year }\end{array}$ \\
\hline $\begin{array}{l}\text { Endothelial } \\
\text { meshwork }\end{array}$ & 101,000 & 60,000 & 683 \\
\hline Anterior meshwork & 195,000 & 107,000 & 1,467 \\
\hline Posterior meshwork & 119,000 & 65,000 & 900 \\
\hline Central meshwork & 348,000 & 171,000 & 2,950 \\
\hline Total meshwork & 763,000 & 403,000 & 6,000 \\
\hline
\end{tabular}

progressive loss of meshwork cells. Presumably part of the answer must be wear-and-tear on the delicate meshwork tissues reducing the life of the weakest of the cell population. The pliable tissue has to withstand the combined effects of a lifetime of contraction and relaxation of the ciliary muscle and alterations in aqueous flow rate through the drainage pathways. ${ }^{16,17}$

Mobilisation and migration of meshwork cells involved in the phagocytosis of materials such as melanin in the circulating aqueous humour may be an additional factor contributing to cell loss from the meshwork. ${ }^{14}$ However, migration of meshwork cells behaving as mobile phagocytes or, for that matter, the death of meshwork cells over indulgent in phagocytosis has been demonstrated more emphatically in some forms of glaucoma than in the normal ageing process. ${ }^{8}$

The meshwork is thought to contain several detoxification enzymes including superoxide dismutase and catalase. ${ }^{18}$ The possibility exists that meshwork cell depletion is either the result of (a) an inability of some meshwork cells to detoxify products carried in the aqueous, or (b) the aqueous becoming progressively deficient in essential components for meshwork cell survival.

The necessity to have a thorough understanding of age related alterations to the cell population of the outflow system is enhanced by recent demonstrations ${ }^{4.89 .10}$ that primary open angle glaucoma may be distinguished by depression of the meshwork cell population beneath that associated with the normal ageing process. Studies of the cell population of the meshwork in different stages and different forms of glaucoma may make a major contribution to our understanding of how the condition affects the outflow pathways.

This work has been supported by the Medical Research Council (Grant No G8301050W). Statistical advice and help was provided by Mr. P. Clark. Secretarial assistance was provided by Miss S. M. Pavitt and Mrs. P. Goodwin.

\section{References}

${ }^{1}$ Rohen JW: new studies on the functional morphology of the trabecular meshwork and outflow channels. Trans. Ophthalmol. Soc. UK. 1969, 89: 431-47.

${ }^{2}$ Rohen JW, Lutjen-Drecoll E: Age changes of the trabecular meshwork in human and monkey eyes. In: Aging and development. Eds. Bredt $\mathrm{H}$ and Rohen JW. F. K. Schattauer Verlag-Stuttgart, New York 1971; 1-36.

${ }^{3}$ Segawa K: Ultrastructural changes of the trabecular tissue in primary open angle glaucoma. Jap. J. Ophthalmol. 1975; 19: 317-38.

${ }^{4}$ Grierson I, Wang Q, McMenamin PG, Lee WR: The effects of age and antiglaucoma drugs on the meshwork cell population. Res. Clin. Forums 1982; 4: 69-92.

${ }^{5}$ Grierson I, Howes RC, Wang Q: Age-related changes in the canal of Schlemm. Exp. Eye Res. 1984; 39: 505-12.

${ }^{6}$ McMenamin PG, Lee WR, Aitken DAN: Agerelated changes in the human outflow apparatus. Ophthalmology 1986; 93: 194-209.

${ }^{7}$ Becker B: The decline in aqueous secretion and outflow facility with age. Am. J. Ophthalmol. 1958; 46: 731-6.

${ }^{8}$ Grierson I: What is Open Angle Glaucoma? Eye 1987; 1: (In Press).

${ }^{9}$ Alvarado J, Murphy C, Polansky J, Juster R: Agerelated changes in trabecular meshwork cellularity. Invest. Ophthalmol. Vis. Sci. 1981; 21: 714-27.

${ }^{10}$ Alvarado J, Murphy C, Juster R: Trabecular meshwork cellularity in primary open-angle glaucoma and nonglaucomatous normals. Ophthalmology 1984; 91: 564-79.

${ }^{11}$ Abercrombie M: Estimation of nuclear population from microtome sections. Anat. Rec. 1946; 94: 239-47.

12 McMenamin PG, Lee WR: Age related changes in extracellular materials in the inner wall of Schlemm's canal. Greafes Arch. Klin. Exp. Ophthalmol. 1980; 212: 159-72.

13 Johnson MD: Do trabecular meshwork cells replicate? Invest. Ophthalmol. Vis. Sci. (Suppl.) 1986; 27: 210.

${ }^{14}$ Rohen JW, Lutjen-Drecoll E: Biology of the trabecular meshwork. In: Basic aspects of glaucoma 
research. Ed. Lutjen-Drecoll E. Schattauer Verlag-Stuttgart, New York 1982; 141-66.

15 Grierson I, Kissun R, Ayad S, Phylactos A, Ahmed $S$, Unger WG: The morphological features of bovine meshwork cells in vitro and their synthetic activities. Graefes Arch. Clin. Exp. Ophthalmol. 1985; 223: 225-36.

${ }^{16}$ Grierson I, Lee WR, Abraham S: The effects of pilocarpine on the morphology of the human out- flow apparatus. Br. J. Ophthalmol. 1978; 62: 302-13.

17 Johnstone MA, Grant WM: Pressure-dependent changes in structures of the aqueous outflow system of human and monkey eyes. Am. J. Ophthalmol. 1973; 75: 365-83.

${ }^{18}$ Freedman S, Anderson PJ, Epstein DL: Superoxide dismutase and catalase in calf trabecular meshwork. Invest. Ophthalmol. Vis. Sci. 1985; 26: 105. 